\title{
Transanal endoscopic microsurgery for rectal adenomas: single center experience
}

\author{
Narimantas Evaldas Samalavicius ${ }^{1}$, Edgaras Smolskas², Kipras Mikelis ${ }^{3}$, Robertas Samalavicius ${ }^{4}$ \\ ${ }^{1}$ Institute of Oncology, Clinic of Internal Diseases, Family Medicine and Oncology of Medical Faculty, Vilnius University, Vilnius, Lithuania \\ ${ }^{2}$ Department of General Surgery, Vilnius University Hospital, Vilnius, Lithuania \\ ${ }^{3}$ School of Medicine, Vilnius University, Vilnius, Lithuania \\ ${ }^{4}$ Second Department of Anesthesia, Intensive Care and Pain Management, Vilnius University Hospital Santariskiu Clinics, Vilnius, Lithuania
}

Videosurgery Miniinv 2016; 11 (1): 26-30 DOI: $10.5114 /$ wiitm.2015.56408

\begin{abstract}
Introduction: Transanal endoscopic microsurgery (TEM) is a method of choice for the local treatment of rectal adenomas. Though generally considered as a safe method, some authors have expressed skepticism about the anorectal function following TEM.

Aim: To review our experience in using TEM for removal of rectal adenomas. We focused on morbidity, local recurrence rates, and anorectal function following the operation.

Material and methods: The study included 72 patients who underwent TEM for rectal adenomas from December 2009 to November 2014 at the Department of Surgical Oncology, National Cancer Institute. Of the 72 patients, 31 (43.1\%) were lost in the follow-up. We recorded the demographics, operative details, final pathology, post-operative length of stay, post-operative complications, recurrences and functional outcome for each of the 41 (56.9\%) remaining participants.

Results: Of the 41 eligible patients, 19 (46.3\%) were male and 22 (53.7\%) were female. The mean age of our patients was 66.8 years. There were no intraoperative complications. In 4 (9.8\%) cases, postoperative complications were observed - urinary retention (2 cases, $4.9 \%$ ) and postoperative hemorrhage (2 cases, $4.9 \%$ ). All complications were treated conservatively. There was a single case (2.4\%) of adenoma recurrence during the follow-up period. The mean score of the FISI questionnaire was $7.6 \pm 9.2$ (ranging from 0 to 36), and the mean Wexner score was $2.3 \pm 3.4$ (ranging from 0 to 17).

Conclusions: Transanal endoscopic microsurgery in our experience demonstrated low complication and recurrence rates, and good functional results. We conclude that TEM is an effective and safe method for the treatment of rectal adenomas.
\end{abstract}

Key words: transanal endoscopic microsurgery, rectal adenomas, recurrence, functional outcome.

\section{Introduction}

Colorectal adenomas are known to lead to colorectal cancer, especially when they possess a villous component and grow larger [1, 2]. As of today, colorectal cancer is the third most common cancer diagnosed in men and women, and it remains in second place as a cause for cancer-related deaths in the Western world [3]. Twenty-nine percent of these carcinomas are located in the rectum [4]. This malignant potential is the reason why removal of rectal adenomas can be associated with a decreased incidence of colorectal cancer [5].

\section{Address for correspondence}

Edgaras Smolskas, Department of General Surgery, Vilnius University Hospital, 29 Siltnamiu St, 04130 Vilnius, Lithuania,

phone: +37 067391376, e-mail: edgaras.smolskas@gmail.com 
For a long time, the most common method for removal of rectal adenomas has been transanal excision. It is a safe method, yet limited to small adenomas of the mid and distal rectum [6]; recurrence rates of up to $60 \%$ have been reported, the most likely cause being fragmentation and positive resection margins $[7,8]$.

Transanal endoscopic microsurgery (TEM) is an endoscopic operation method for local excision of rectal adenomas. It was developed by G. Buess in Tubingen, Germany in 1983, and since then TEM has been shown to be a safe method for removing larger adenomas not only from distal parts of the rectum, but also from the proximal rectum and distal sigmoid colon $[9,10]$. The recurrence rate is lower than that of transanal excision [11]. Transanal endoscopic microsurgery advantages are attributed to the technology that permits a stable and clear view throughout all of the rectum and allows precise excision $[9,12]$.

Though generally considered a safe method, some studies have expressed skepticism regarding the anorectal function following TEM, mainly because the procedure involves the insertion of a $40 \mathrm{~mm}$ diameter operative rectoscope, sometimes for prolonged periods, which may disturb sphincter function [13-15]. Few studies have used validated functional assessment tools to evaluate the changes in defecation of patients prior to and after TEM $[16,17]$.

\section{Aim}

The purpose of this study is to review our single center experience in removal of rectal adenomas using TEM. We focused on morbidity, local recurrence rates and anorectal function following the operation.

\section{Material and methods}

The study design included patients who underwent TEM for rectal adenomas from December 2009 to November 2014 at the Department of Surgical Oncology, National Cancer Institute, Vilnius, Lithuania. Patients were excluded if they had another pathologic diagnosis, were followed for fewer than 6 months, or did not complete functional assessment tools.

All patients were evaluated pre-operatively according to a standard protocol including physical and endoscopic examination and tumor biopsy, and some patients had an endorectal ultrasound. Tumor location was defined as the distance from the den- tate line to the lower edge of the tumor, and diameter as the largest diameter of the tumor.

We recorded the demographics, operative details, final pathology, post-operative length of stay, post-operative complications, recurrence, and functional outcome for each participant. We evaluated the functional outcome by means of a detailed questionnaire based on the Faecal Incontinence Severity Index (FISI) and the Wexner scale. The FISI, developed by Rockwood, uses two basic components: the type of incontinence and its frequency. FISI scores range from 0 (total continence) to 61 (complete incontinence). The Wexner fecal incontinence scale takes into account five parameters that are scored on a scale from zero (absent) to four (daily), regarding the frequency of incontinence with respect to: gas, liquid, solid, use of pad, and quality of life. Full continence is a Wexner total of zero (0), whereas full incontinence is a Wexner total of 20.

The questionnaire was sent to 72 patients for self-completion. The study participants were informed of the objectives of this questionnaire and confidentiality policy. Of the 72 patients, 31 (43.1\%) were lost to follow-up. Data from the 41 (56.9\%) patients who responded to the questionnaires was obtained and evaluated.

All operations were performed under general anesthesia, in lithotomy, prone jackknife, left lateral or right lateral position, depending on the exact location of the tumor. Standard TEM equipment was used. Full thickness excision with a $1 \mathrm{~cm}$ safety margin was attempted, followed by closure of the rectal wall defect in one layer by running a monocryl 3-0 suture using silver clips.

Follow-up was performed under our institutional guidelines: a proctoscopy after 3 months, and a colonoscopy 1 year and 3 years after surgery. All patients were followed up with flexible colonoscopy at 12 months and at 36 monthly intervals thereafter.

\section{Results}

Of the 41 eligible patients, 19 (46.3\%) were male and 22 (53.7\%) were female. The mean age of our patients was 66.8 years (ranging from 48 to 93 years) (Table I). There were no complications during the TEM procedure for any of the patients; however, in one case $(2.4 \%)$ it was necessary to perform an additional operation during the same hospital stay: laparoscopic ileocecal resection due to gross adenoma. In 
Table I. Demographic data

\begin{tabular}{|lc|}
\hline Parameter & Results \\
\hline Gender, $n(\%):$ & $41(100)$ \\
\hline Male & $19(46.3)$ \\
\hline Female & $22(53.7)$ \\
\hline Age, mean \pm SD, range [years] & $66.8 \pm 10.3,48-93$ \\
\hline
\end{tabular}

Table II. Operation characteristics

\begin{tabular}{|lc|}
\hline Parameter & Results \\
\hline Additional operations: & \\
\hline Laparoscopic ileocecal resection & $1(2.4 \%)$ \\
\hline Morbidity & $4(9.8 \%)$ \\
\hline Urinary retention & $2(4.9 \%)$ \\
\hline Bleeding & $2(4.9 \%)$ \\
\hline Postoperative hospital stay, & $2.34 \pm 1.90$, \\
mean \pm SD, range [days] & $1-8$ \\
\hline Conversion rate & $0(0 \%)$ \\
\hline Postoperative mortality rate & $0(0 \%)$ \\
\hline Recurrence & $1(2.4 \%)$ \\
\hline
\end{tabular}

Table III. Adenoma characteristics

\begin{tabular}{|lc|}
\hline Parameter & Results \\
\hline $\begin{array}{l}\text { Transverse diameter, mean } \pm \text { SD, } \\
\text { range }[\mathrm{cm}]\end{array}$ & $\begin{array}{c}2.98 \pm 1.52, \\
1.0-8.3\end{array}$ \\
\hline $\begin{array}{l}\text { Distance from dentate line, } \\
\text { mean } \pm \text { SD [cm]: }\end{array}$ & $8.24 \pm 3.12$ \\
\hline $0-5$ & $7(17.1 \%)$ \\
\hline $5-10$ & $22(53.7 \%)$ \\
\hline $10-15$ & $11(26.8 \%)$ \\
\hline$>15$ & $1(2.4 \%)$ \\
\hline Pathology: & $6(14.6 \%)$ \\
\hline Tubular adenoma & $1(2.4 \%)$ \\
\hline Villous adenoma & $24(58.5 \%)$ \\
\hline Tubulovillous adenoma & $10(24.5 \%)$ \\
\hline Carcinoma in situ & $7(17.1 \%)$ \\
\hline Margins: & $34(82.9 \%)$ \\
\hline Positive or indeterminate & $2(4.9 \%)$ \\
\hline Negative & $33(95.1 \%)$ \\
\hline Fragmentation: & \\
\hline Fragmented & \\
\hline Whole & \\
\hline
\end{tabular}

$4(9.8 \%)$ cases, postoperative complications were observed - urinary retention ( 2 cases, $4.9 \%$ ) and postoperative hemorrhage ( 2 cases, $4.9 \%$ ), all of which were treated conservatively. The conversion rate of the TEM procedure and the postoperative mortality rate were $0 \%$. The mean postoperative hospital stay was 2.34 days (ranging from 1 to 8 days); the mean follow-up time was $32.8 \pm 19.1$ months (ranging from 8 to 67.5 months). A single case (2.4\%) of adenoma recurrence was found during the follow-up period (Table II).

The mean diameter of adenomas removed was $2.98 \pm 1.52 \mathrm{~cm}$ (ranging from 1.0 to $8.3 \mathrm{~cm}$ ). The mean distance from the dentate line was $8.24 \pm 3.12 \mathrm{~cm}$. The rectum was subdivided into three parts: distal (0-5 cm from the dentate line), mid $(5-10 \mathrm{~cm})$, and proximal (10-15 cm). Most adenomas, i.e. $22(53.7 \%)$, were located in the mid-rectum, 7 (17.1\%) in the proximal rectum, $11(26.8 \%)$ in the distal rectum, and $1(2.4 \%)$ in the sigmoid colon $18 \mathrm{~cm}$ from the dentate line (Table III).

The histological examination revealed that 25 (58.5\%) adenomas were tubulovillous, 6 (14.6\%) were tubular adenomas, 1 (2.4\%) was a villous adenoma, and 10 (24.5\%) were defined as carcinoma in situ. In 35 (82.9\%) cases the resection margins were negative; the rest were either positive or impossible to determine. Microscopic examination also showed that 39 (95.1\%) specimens were excised whole, and $2(4.9 \%)$ were fragmented during the operation (Table III).

The mean score of the FISI questionnaire was $7.6 \pm 9.2$ (ranging from 0 to 36 ), and the mean Wexner score was $2.3 \pm 3.4$ (ranging from 0 to 17 ). The two scores showed a strong correlation with each other (correlation coefficient 0.95, $p<0.05$ ).

\section{Discussion}

Nowadays, transanal endoscopic microsurgery has become the most viable alternative to the transanal approach in the treatment of rectal adenomas. Various articles have been published demonstrating different postoperative morbidity rates, ranging from $11.8 \%$ to $17 \%$ for transanal excision, and $7.6 \%$ to $15 \%$ for TEM [18, 19]; however, De Graaf's 2009 study was the first to find statistically significant differences when comparing the safety of these procedures a $5.3 \%$ postoperative morbidity rate after TEM, and $10 \%$ after transanal excision [11]. In our study, we had $4(9.8 \%)$ cases of postoperative morbidity, which 
compares well with the results from other authors. All of these complications were relatively common and easily treatable by conservative methods - urinary function for the patients who experienced retention was restored using urinary catheterization, and postoperative bleeding was treated by intravenous fluid infusions and blood transfusions. Furthermore, not a single TEM procedure was converted into laparoscopy or an open operation, thus showing its suitability for treatment of rectal adenomas.

Transanal endoscopic microsurgery has also been found to have lower recurrence rates - recurrence rates of transanal excision range from $4 \%$ to $57 \%$ and $3 \%$ to $16 \%$ in TEM [11]. Among the main factors that affect recurrence after these operations are incomplete excision and fragmentation of acquired specimens $[8,20]$. Transanal endoscopic microsurgery was shown to be more likely to provide clear resection margins and less fragmentation than the transanal approach, which could be the reason for lower recurrence rates with TEM. Our results regarding the fragmentation rate were similar to those described by other authors; however, the rate of positive resection margins found in our study was higher: we found $4.9 \%$ fragmented specimens and $17.1 \%$ positive or unclear resection margins, which contrasts with the results of de Graaf et al. (1.4\% fragmentation and $12 \%$ clear resection margins) and Moore et al. (6\% fragmentation, $10 \%$ clear resection margins) $[11,19]$. Concerning the higher rate of positive or unclear resection margins, it is unclear how many of the specimens in the "unclear" category were actually positive or negative. It is important to take into consideration that the main surgical method for excising adenomas was coagulation, which can distort margins and make them unclear; therefore the actual number of positive resection margins is most likely lower than reported. In either case, the recurrence rate was not affected by these findings - we found one (2.4\%) local recurrence during our follow-up, which was lower than that described by other authors and proves the effectiveness of this method for rectal adenoma removal $[8,10,11$, 19-21].

A few authors have expressed concern whether TEM has a negative impact on rectal function. The main concern is that the procedure involves the insertion of a $40 \mathrm{~mm}$ diameter rectoscope, sometimes for prolonged periods. This has been found to affect continence over time - Kreis et al. described a drop in anal squeeze pressure that returned to normal within a year and a permanent decrease in resting pressure, all of which they attributed to the mechanical trauma from the $40 \mathrm{~mm}$ diameter proctoscope [22]. Studies by Herman et al. and Kennedy et al. both used ultrasound as part of their studies to detect sphincter defects after TEM and found no changes in sphincter width or length, and thus concluded that the prolonged operation times can result in increased risk of sphincter damage, but without clinical consequences [14, 23]. A few studies have used validated surveys such as the Fecal Incontinence Severity Index (FISI) or the Wexner fecal incontinence score to measure the severity of patients' incontinence by focusing on the way patients perceive the functional changes that follow TEM. Cataldo et al. found no changes in fecal incontinence following TEM, whereas Doornebosch et al. concluded that TEM itself does not improve or decrease anorectal function, but the removal of the tumor - especially a low lying tumor - does result in improved continence $[16,17]$. Our results correspond with the data from other authors - both FISI and Wexner scores were relatively low, and correlated well with each other, which means that our patients understood the questionnaires and answered them correctly. The slightly higher incontinence results were consistent with the patients' age, which could be explained by the deteriorated anorectal function before the operation and slower recovery after TEM in elderly patients.

\section{Conclusions}

A previous study by our clinic had already shown TEM to be an alternative to the transanal approach when treating benign rectal masses, and since then it has become the procedure of choice for the treatment of rectal adenomas [24]. The low recurrence rates, low complication rates, and good functional results after the operation allow us conclude that TEM is an effective and safe method for the treatment of rectal adenomas.

\section{Conflict of interest}

The authors declare no conflict of interest.

\section{References}

1. Morson B. The Polyp-cancer sequence in the large bowel. J R Soc Med 1974; 67: 451-7. 
2. De Leon MP, Di Gregorio C. Pathology of colorectal cancer. Dig Liver Dis 2001; 33: 372-88.

3. Siegel RL, Miller KD, Jemal A. Cancer statistics 2015. CA Cancer J Clin 2015; 65: 5-29.

4. Amann M, Modabber A, Burghardt J, et al. Transanal endoscopic microsurgery in treatment of rectal adenomas and $\mathrm{T} 1$ lowrisk carcinomas. World J Surg Oncol 2012; 10: 1-8.

5. Winawer SJ, Zauber AG, Ho MN, et al. Prevention of colorectal cancer by colonoscopic polypectomy. N Engl J Med 1993; 329: 1977-81.

6. Parks AG, Stuart AE. The management of villous tumors of the large bowel. Br J Surg 1973; 60: 688-95.

7. Janssen KM, Mazee HA, Ruers TJ, et al. Transanal resection of large sessile rectal polyps. Nederlands Tvoor Geneeskunde 1996; 140: 1646-9.

8. McCloud JM, Waymont N, Pahwa N, et al. Factors predicting early recurrence after transanal endoscopic microsurgery excision for rectal adenoma. Colorectal Dis 2006; 8: 581-5.

9. Buess G, Theiss R, Hutterer F, et al. Die transanale endoscopische Rektumoperation. Erprobung einer neuen Methode im Tierversuch. Leber Magen Darm 1983; 13: 73-7.

10. De Graaf EJR, Doornebosch PG, Tetteroo GW, et al. Transanal endoscopic microsurgery is feasible for adenomas throughout the entire rectum: a prospective study. Dis Colon Rectum 2009; 52: 1107-13.

11. De Graaf EJR, Burger JWA, van ljsseldijk ALA, et al. Transanal endoscopic microsurgery is superior to transanal excision of rectal adenomas. Colorectal Dis 2011; 13: 762-7.

12. De Graaf EJR. Transanal endoscopic microsurgery. Scand I Gastroenterol Suppl. 2003; 239: 34-9.

13. Hemingway D, Flett M, McKee RF, et al. Sphincter function after transanal endoscopic microsurgical excision of rectal tumors. Br J Surg 1996; 83: 51-2.

14. Herman RM, Richter P, Wałęga P, et al. Anorectal sphincter function and rectal barostat study in patients following transanal endoscopic microsurgery. Int J Colorectal Dis 2001; 16: 370-6.

15. Speakman CT, Burnett SJ, Kamm M, et al. Sphincter injury after anal dilatation demonstrated by anal endosonography. $\mathrm{Br}$ J Surg 1991; 78: 1429-30.

16. Cataldo PA, O’Brien S, Osler T. Transanal endoscopic microsurgery: a prospective evaluation of functional results. Dis Colon Rectum 2005; 48: 1366-71.

17. Doornebosch PG, Gosselink MP, Neijenhuis PA, et al. Impact of transanal endoscopic microsurgery on functional outcome and quality of life. Int J Colorectal Dis 2008; 23: 709-13.

18. Langer C, Liersch T, Suss M, et al. Surgical cure for early rectal carcinoma and large adenoma: transanal endoscopic microsurgery (using ultrasound or electrosurgery) compared to conventional local and radical resection. Int J Colorectal Dis 2003; 18: 222-9.

19. Moore JS, Cataldo PA, Osler T, et al. Transanal endoscopic microsurgery is more effective than traditional transanal excision for resection of rectal masses. Dis Colon Rectum 2008; 51: 1026-30.

20. Whitehouse PA, Tilney HS, Armitage J, et al. Transanal endoscopic microsurgery: risk factors for local recurrence of benign rectal adenomas. Colorectal Dis 2006; 8: 795-9.
21. Guerrieri M, Baldarelli M, Morino M, et al. Transanal endoscopic microsurgery in rectal adenomas: experience of six Italian centers. Dig Liver Dis 2006; 38: 202-7.

22. Kreis ME, Jehle EC, Haug V, et al. Functional results after transanal endoscopic microsurgery. Dis Colon Rectum 1996; 39: 1116-21.

23. Kennedy ML, Lubowski DZ, King DW, et al. Transanal endoscopic microsurgery excision: is anorectal function compromised? Dis Colon Rectum 2002; 45: 601-4.

24. Samalavicius NE, Kilius A, Petrulis K, et al. Transanal endoscopic microsurgery: results of the first 50 cases. Acta Medica Lituanica 2012; 19: 45-9.

Received: 20.10.2015, accepted: 21.11.2015. 